\title{
Prevalence of Anaemia among OPD Patients of a Tertiary Care Hospital of Eastern India
}

\author{
Debjit Chattopadhyay ${ }^{1}$, Shouvanik Adhya ${ }^{2}$ \\ (Department of Pathology, College of Medicine \& JNM Hospital, WBUHS, Kalyani, West Bengal, India) \\ (Department of Forensic Medicine \& Toxicology, College of Medicine \& JNM Hospital, WBUHS, Kalyani, West \\ Bengal, India)
}

\begin{abstract}
Prevalence of anaemia is very high in tertiary care hospital O.P.D. patients. Reproductive age group female, adolescence females and children are the main victims. The present India government strategies and programmes are not sufficient to control the growing menace of anaemia. So newer strategies and target groups must be formulated.
\end{abstract}

Keywords: Anaemia, Prevalence, cross sectional study, unicentric study

\section{Introduction}

According to WHO anaemia is the qualitative and or quantitative diminution of haemoglobin or RBC or both in respect to the age and sex of the individual and as per Robbins ${ }^{[1]}$ anaemia is defined as a reduction of the total circulating red cell mass below normal limits. Anaemia is a major problem in India spatially in pregnant women but young adult women between the ages 15 to 25 where who are nonpregnant are also especially vulnerable to anaemia. Though anaemia is less common among male but they also suffer from anaemia in a considerable extent to their counterpart in developed countries. Adverse effects of anaemia are various as for example on nervous system on physical response to diseases physiological stressed condition like pregnancies and the like Iron, vit B12 and folate deficiencies are the common causes of anaemi. Anaemia is wide spread in India but it varies in civierity from state to state and zone to zone. Poor die, lack of sense of hygiene which use to warm infestations, lack of health consciousness social taboos and poor economic status all contributes to overwhelming prevalence of anaemia .Our objective is to show the prevalence of anaemia even in a tertiary health care centre. Majority of the anaemia can be treated in primary or secondary health care system. Even primordial prevention can arrest a sizable number of anaemia before development. Despite of different programmes taken by the government for primary and primordial prevention of anaemia among vulnerable groups the prevalence is on the rise so we want to focus on the prevalence so that newer innovative and effective methods can be taken against this growing menace.

\section{Materials And Methods}

1.Ethical consideration :-permission is taken from the ethics committee

2.Finance:-finance is done by self and it is about $1500 /-$

3.Type of study:-cross sectional and unicentric study

4.Sample size: 1902 patients

5.Duration of study: March 2013 - June 2013

6.Place of study:College of Medicine and J.N.M. Hospital,Kalyani,Nadia

7.Selection of cases:The OPD patients who were sent for estimation of haemoglobin and were estimated in the central Pathological laboratory of this hospital.

8.Estimation of haemoglobin:- Haemoglobin is estimated using cyanmethaemoglobin method with the help of Drabkin`s solution and colorimeter(method is taken from Dacie\& Lewis- practical haematology) ${ }^{[2]}$

9. The patients are divided into 7 sub-groups $<13$ years(paediatric age group),13-18 years(teen age group), $>18-$ 30 (young adults), $>30-40$ (adults),$>40-50$ (adults) $>50-60$ (late adults and old ages), $>60-70$ (geriatric group) and $>70$ (old age).

As anaemia is very prevalent in India cut off mark for haemoglobin is lowered. $<7 \mathrm{gm} \%$ means severe anaemia, $7-10 \mathrm{gm} \%$ (moderate to mild anaemia), $>10-13 \mathrm{gm} \%$ (low normal to normal), $>13-15 \mathrm{gm} \%$ (absolutely normal), and $>15 \mathrm{gm} \%$ (very healthy level).

\section{Results}

Table no. 1 shows total number of cases 1902 of which 761 patients are male and 1141 patients are female. i.e. $40.01 \%$ are male and $59.99 \%$ are female. Table no 2 shows $15.08 \%$ cases are less than 13 year of age i.e. paediatric age group (287), $7.46 \%$ cases belong to $13-18$ years, $24.60 \%$ cases belong to $>18-30$ years i.e. young adult group $(468), 17.50 \%$ cases belong to $>30-40$ years, $15.29 \%$ cases belong to $>40-50$ years, 
$10.8 \%$ cases belong to $>50-60$ years, $6.51 \%$ cases belong to $>60-70$ years, $2.61 \%$ cases belongs to greater than 70 years i.e. old age group. Table no 3 shows less than $7 \mathrm{~g} \%$ i.e. severe anaemia in $1.78 \%$ cases $\& 7-10 \mathrm{~g} \%$ i.e. mild to moderate anaemia in $31.75 \%$ cases. Table- 4 shows the percentage of patients of different religions. Table -5 shows prevalence of anaemia in males and females of different age groups.

From table-1 we can see $59.99 \%$ patients are females and it is obvious because menstruation pregnancies make women more vulnerable to anaemia. Table- 2 shows $15.08 \%$ patients belong to $<13$ years i.e paediatric age group and we can also see from table- 5 that of these paediatric age patients 3 males and 2 females are severely anaemic ,60 males and 52 females are mild to moderately anaemic and107 males 64 females are non-anaemic.We can infer that 117 patients are anyhow anaemic and170 children are non-anaemic.We can see that $40.76 \%$ of paediatric age group are anaemic. In the 13-18 year group28 out of total 34 anemics are females i.e $82.35 \%$. Similarly 120 out of 468 in $>18-30$ years group are anaemic that means $25.64 \%$ of which 107 i.e $89 \%$ of total anaemics are females. 117 out of 333 patients are anaemic in $>30-40$ years i.e35.13\%and again 106 that means more than $90 \%$ of the total anaemics are females. Likewise in the $>40-50$ years age group out of total291 patients 111 patients or $38.14 \%$ patients are anaemic and from analysis it is clear that out of total anaemic patients 97 i.e more than $87 \%$ are females. In $>50-60$ year group total67 patients out of 206 are anemic ie $32.5 \%$ anemic and 49 i.e $73.13 \%$ of total anemics are females. In $>60-70$ year group 56 outof 124 i.e $45.16 \%$ are anemic and among the anemics 33 i.e $58.92 \%$ are females. In $>70$ years group16 in 51 i.e31.37\% are anemic and 11 i.e68.75\% among the anemics are females.

\section{DISCUSSION}

So we can conclude that except $<13$ years age group that means paediatric age group, females are well ahead of males in the population of anemics and this problem is Himalayan in $13-,<18$ year age group- $82.35 \%$; $>18-30$ years $89 \%$; in $>30-40$ year group $>90 \% ;>40-50$ year group $87 \% ;>50-60$ year group $73 \%$. So from teenage to socially active and productive age groups anemia is almost exclusively prevalent in females and this feature led many researchers and workers like R.G. Viveki, A.B. Halappanavar etal ${ }^{[3]}$ to concentrate on prevalence of anemia in pregnant woman.Prevalence of nutritional anamia in pregnant woman is Indias major problem.33-89\% among pregnant women are anaemic.Among adolecense girl $60 \%$ s are anaemic as observed by Tote ja G.S etal. ${ }^{[4]}$ In our observation $82.35 \%$ of all anaemic patients belonging to $>13-18$ years group are females. Priyali Pathak et a ${ }^{[5]}$ observed micronutrient deficiency in diet like zink,iron, folate,iodine etc in pregnant women are the causes of low birth weight babies and there is no denying the fact the low birth weight babies contribute to prevalence of anaemia in paediatric age group which is according to a observation $40.76 \%$ patients of paediatric age group as estimated in our laboratory . Bharati et $\mathrm{al}^{\left[{ }^{[6]}\right.}$ observed that non pregnant females below age 25 years and 15 to 49 age of pregnant females are anaemic. Acccording to Dr. Vijaynath et $\mathrm{al}^{[7]}$ iron deficiency anaemia has deleterious effect on mother and fetus. Literacy,occupation,consumption of iron,vit B12,folate,parity,fertility all counts in the development of anaemia and this is also seconded by K.N. Agarwal et $a^{[8]}$. Vetegetarian and girls specially after menarchae are at risk for development of anaemia as observed by Verma M. et al ${ }^{[9]}$. In our hospital patients usually live on vegetarian diets not for habit but for proverty in most of the cases. Also the population the hospital usually caters are young. So prevalence of anaemia is evident in this age group here. Moreover poor sense of hygiene,going to naturs call bare footed injesting contaminated pond water in the name of God etc contribute to warm infestation including hook worms and cause cronic iron deficiency and megaloblastic anaemia. As eastern zone of India is a thalassemia endemic zone,both carrier and mildly or overtly diseased are also anaemic. Muslim patients are less in numbers that does not mean that they are more healthy but this is because less health consciousness and education. So there is less turn up of muslim patients in hospitals.

TABLES

Table 1: Sex ratio among cases

\begin{tabular}{|l|l|l|}
\hline Sex & No of cases & Percentage of total cases \\
\hline Male & 761 & $40.01 \%$ \\
\hline Female & 1141 & $59.99 \%$ \\
\hline Total & 1902 & $100 \%$ \\
\hline
\end{tabular}

Table 2: Age distribution of cases

\begin{tabular}{|l|l|l|}
\hline Range of age & No. of cases & percentage \\
\hline Less than13 years & 287 & $15.08 \%$ \\
\hline $13-18$ years & 142 & $7.46 \%$ \\
\hline $18-30$ years & 468 & $24.6 \%$ \\
\hline $30-40$ years & 333 & $17.5 \%$ \\
\hline $40-50$ years & 291 & $15.29 \%$ \\
\hline $50-60$ years & 206 & $10.8 \%$ \\
\hline $60-70$ years & 124 & $6.51 \%$ \\
\hline
\end{tabular}


Prevalence of Anaemia among OPD Patients of a Tertiary Care Hospital of Eastern India

\begin{tabular}{|l|l|l|}
\hline Above 70 years & 51 & $2.61 \%$ \\
\hline Total & 1902 & $100 \%$ \\
\hline \multicolumn{2}{|c|}{ Table 3: Distribution of cases according to blood Hb gm $\%$} \\
\hline Hb level (gm\%) & No of cases & Percentage \\
\hline$<7$ & 34 & $1.78 \%$ \\
\hline $7-10$ & 604 & $31.75 \%$ \\
\hline$>10-13$ & 1131 & $59.46 \%$ \\
\hline$>13-15$ & 124 & $6.51 \%$ \\
\hline$>15$ & 9 & $0.47 \%$ \\
\hline Total & 1902 & $100 \%$ \\
\hline
\end{tabular}

Table 4: Distribution of cases according religion

\begin{tabular}{|c|l|l|}
\hline Religion & No of cases & percentage \\
\hline Hinduism & 1711 & $89.95 \%$ \\
\hline Islam & 174 & $9.14 \%$ \\
\hline Others & 17 & $0.89 \%$ \\
\hline
\end{tabular}

Table 5: Prevalence of anaemia in males and females of different age groups

\begin{tabular}{|c|c|c|c|c|c|c|c|c|c|c|}
\hline \multirow{2}{*}{$\begin{array}{l}\text { Hb level } \\
\text { Age } \\
\text { (years) }\end{array}$} & \multicolumn{2}{|c|}{$<7 \mathrm{gm} \%$} & \multicolumn{2}{|c|}{$7-10 \mathrm{gm} \%$} & \multicolumn{2}{|c|}{$>10 \mathrm{gm} \%-13 \mathrm{gm} \%$} & \multicolumn{2}{|c|}{$>13 \mathrm{gm} \%-15 \mathrm{gm} \%$} & \multicolumn{2}{|c|}{$>15$ gm $\%$} \\
\hline & Male & Female & Male & Female & Male & Female & Male & Female & Male & Female \\
\hline$<13$ & 3 & 2 & 60 & 52 & 101 & 59 & 5 & 3 & 1 & 1 \\
\hline $13-18$ & 1 & 0 & 5 & 28 & 45 & 47 & 13 & 3 & 0 & 0 \\
\hline$>18-30$ & 0 & 2 & 13 & 105 & 114 & 190 & 35 & 8 & 1 & 0 \\
\hline$>30-40$ & 1 & 6 & 10 & 100 & 49 & 137 & 26 & 2 & 2 & 0 \\
\hline$>40-50$ & 1 & 5 & 13 & 92 & 70 & 98 & 9 & 1 & 1 & 1 \\
\hline$>50-60$ & 5 & 4 & 13 & 45 & 60 & 62 & 14 & 2 & 0 & 1 \\
\hline$>60-70$ & 1 & 2 & 22 & 31 & 37 & 28 & 1 & 2 & 0 & 0 \\
\hline$>70$ & 1 & 0 & 4 & 11 & 24 & 10 & 0 & 0 & 0 & 1 \\
\hline
\end{tabular}

\section{Conclusion}

So from this results and analysis and discussion we can safely conclude that prevalence of anaemia in O.P.D. patients of our hospital is alarmingly high and as it is a part of India the problem cannot be separately solved. Despite different strategies and programs have been taken by government of India the growing menace of anaemia is not solved. So newer strategies must be taken. Adolescent girls and paediatric age group should be targeted.

\section{Acknowledgement}

I am indebted to Mr. Sudip Das \& Mr. Shubhrasouma Das, 3rd semester MBBS students of College of Medicine and JNM Hospital, WBUHS, Kalyani, Nadia for immense help in preparation of this article.

\section{References}

[1]. Robbins and Cotran's Pathogenic basis of disease;8th edition Editors-Kumar,Abbas,Fausto,Aster: Publisher: Elsevier Saunders:printed in India 2010: Page 639.

[2]. Dacie \& Lewis practical haematology 10th edition ; Publisher Churchill livingstone :2006 ; page 27-29

[3]. R.G. Viveki, A.B. Halappanavar et al :Prevalence of anaemia and its epidemiological determinants in pregnant women :AJMS Al Ameen J. Med Sci(2012)5(3):216-223;SS CODEM:AAJMBG

[4]. Toteja, G.S. Singh, Padam et al: Open Access Prevalence of anaemia among pregnant women and adolescent girls in 16 districts of India: Source: Food \& Nutrition Bulletin, Volume 27, Number 4, December 2006, pp. 311-315(5)

[5]. Publisher: Nevin Scrimshaw International Nutrition Foundation

[6]. Priyali pathak ,Umesh Kapil, Renu Saxena et al: Prevalence of multiple micronutrients deficiencies amongst pregnant women in a rural area of Haryana :Indian Journal of Paediatrics;November2004,Vol-71,Issue-11 ;PP-1007-1014

[7]. Bharati Premananda,Suparna et al:Prevalence of anemia and its determinants among pregnant and non-pregnant women in India:Asia Pacific Journal of public health:20(4)PP-347-359:ISSN1-800-818-7243URL-http//aph.sagepub.com/cgi/content/abstract/20/4/347

[8]. Dr.Vijaynath,Patil et al:Prevalence of anaemia in pregnancy:Indian Journal of applied basic medical sciences:Year 2010, Vol12B,Issue-15,Print:ISSN:O975-8917

[9]. K.N. Agarwal,D.K Agarwal,K Sharma et al:Prevalence of anaemia in pregnant and lactating mother in India:Indian J. Med Res 24,August 2006,PP.-173-184

[10]. Verma M,Chhatwal J, Kaur G. et al: Prevalence of anaemia among urban school children of Punjab :Indian Paediatr 1998 Dec,35(12):1181-6 